\title{
DISPONIBILIDADE HÍDRICA E BALANÇO HÍDRICO DA BACIA DO RIO CACHOEIRA NA REGIÃO DE ITABUNA / BA
}

\author{
WATER AVAILABILITY AND HYDRIC BALANCE OF THE CACHOEIRA RIVER WATERSHED \\ IN THE REGION OF ITABUNA / BA
}

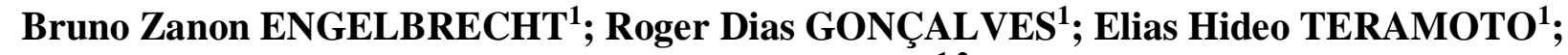 \\ Hung Kiang CHANG ${ }^{1,2}$ \\ ${ }^{1}$ Laboratório de Estudos de Bacias (LEBAC), UNESP - Campus de Rio Claro. Centro de Estudos Ambientais (CEA), UNESP - \\ Campus de Rio Claro. Rio Claro - SP. E-mails: bruno_zenon2@ hotmail.com; rdgon@ hotmail.com; elias.hideo_teramoto@unesp.br \\ ${ }^{2}$ Departamento de Geologia Aplicada (DGA), UNESP - Campus de Rio Claro. Rio Claro - SP \\ E-mail: chang.hung-kiang@ unesp.br \\ Introdução \\ Caracterização da Área de Estudo \\ Materiais e Métodos \\ Estações Pluviométricas e Fluviométricas \\ Disponibilidade Hídrica \\ Balanço Hídrico \\ Resultados \\ Balanço Hídrico \\ Disponibilidade Hídrica Superficial \\ Discussões \\ Conclusões \\ Referências
}

\begin{abstract}
RESUMO - Foi estimado o balanço hídrico na Bacia do Rio Cachoeira, na região de Itabuna (Sul da Bahia), para o período de 1973 a 2005, utilizando-se a série histórica de vazão do Rio Cachoeira e a precipitação acumulada nesse período, com base em dados obtidos de cinco estações pluviométricas. Para o cálculo dos escoamentos de base e superficial foi aplicada a técnica de filtros digitais, que permite separar, de maneira automatizada e sistemática, a contribuição das componentes fluxo de base e escoamento superficial. A evapotranspiração acumulada anual média da bacia hidrográfica corresponde a cerca de $85 \%$ da precipitação, enquanto $15 \%$ desta corresponde ao escoamento total. O escoamento superficial representa a maior parcela da água escoada, com média anual de $84,53 \%$ e máximo de $92,2 \%$ no período chuvoso, indicando baixa capacidade de infiltração de água no subsolo. A recarga média anual estimada para o aquífero $(27.35 \mathrm{~mm} / \mathrm{a})$ corresponde a $15 \%$ da vazão média do rio Cachoeira e a 2,34\% da precipitação média anual.

Palavras-chave: Aquíferos cristalinos, Balanço hídrico, Estresse hídrico, Itabuna (BA), Bacia do Rio Cachoeira.
\end{abstract}

\begin{abstract}
The water balance calculation was carried out for the period from 1973 to 2005 in the Cachoeira River Basin, located in the south of Bahia state. Using the time series data of the Cachoeira River flow and the accumulated precipitation was calculated based on the data from five rainfall stations. For the calculation of the base and superficial flows the digital filter technique was applied, which allows to separate in an automated and systematic way the contribution of the components base flow and surface flow. The average annual cumulative evapotranspiration of the catchment area corresponds to about $85 \%$ of the precipitation, while $15 \%$ of it is drained by the rivers. The runoff represents the largest part of the water flowed by the rivers, with an annual average of $84.53 \%$ and a maximum of $92.2 \%$ in the rainy season and indicates the low water infiltration capacity in the subsoil. The estimated annual average recharge for the aquifer $(27.35 \mathrm{~mm} / \mathrm{y})$ corresponds to $15 \%$ of the average flow of the Cachoeira river and $2.34 \%$ of the average annual rainfall.
\end{abstract}

Keywords: Crystalline aquifers, Water balance, Hydric stress, Itabuna, Cachoeira River Watershed.

\section{INTRODUÇÃO}

Os recursos hídricos são vitais para a subsistência humana e são igualmente importantes para o desenvolvimento social e econômico, sendo utilizados para abastecimento público, irrigação e utilização na indústria. Segundo projeções de Rijsberman (2006), a escassez de água será um fator limitante para a produção de alimentos em diversas partes do mundo, em um futuro próximo. Face à abundância de aquíferos fissurais e à crescente demanda de água no mundo, o entendimento dos processos que governam o fluxo e o armazenamento de água em rochas fraturadas têm adquirido relevância cada vez maior, particularmente em países subdesenvolvidos (Gustafson \& Krásný, 1994). É condição mandatória para a adequada gestão deste recurso o conhecimento da quantidade de água que flui em uma bacia e sua taxa de reposição, o que torna desafiadora a gestão deste recurso em terrenos cristalinos, dada a complexidade dos mecanismos que governam o fluxo neste tipo de terreno geológico (Berkowitz, 2002).

Como pontuado por diversos autores, destacando-se Dewandel et al. (2006), Gleeson et 
al. (2009), Guihéneuf et al. (2014) e Engelbrecht (2017), o fluxo de água em terrenos cristalinos envolve elevado grau de incertezas. Tais incertezas são decorrentes da dificuldade de se caracterizar adequadamente a conectividade e das propriedades hidráulicas das descontinuidades geológicas que armazenam e transmitem água em subsuperfície (Guihéneuf et al., 2014). O estudo de bacias hidrográficas em terrenos cristalinos é igualmente complexo, uma vez que congregam características distintas daquelas observadas em aquíferos porosos e permeáveis. Dada a distribuição espacial restrita das descontinuidades geológicas (fraturas, juntas etc.), o volume de água que nelas infiltra e promove recarga do aquífero é bastante limitado (Gleeson et al., 2009; Chesnaux, 2013), de forma que as taxas de escoamento superficial são proporcionalmente elevadas. Em razão de tais características, as curvas de permanência dos rios instalados em terrenos cristalinos são marcadas por vazões reduzidas no período de recessão, sucedidos por aumentos abruptos de vazão em períodos chuvosos.

A região de Itabuna (BA), situada em um terreno cristalino, está sujeita a estresse hídrico devido à baixa abundância de águas superficiais e subterrâneas, intensificada pela recorrente seca na região. Em decorrência da escassez de estudos na Bacia do Rio Cachoeira, inexistem subsídios técnicos para o planejamento e manejo dos recursos hídricos superficiais e subterrâneos, persistindo incertezas quanto ao volume de água que pode ser explorada de maneira sustentável. Para apresentar um diagnóstico quantitativo do volume água que circula na bacia do Rio Cachoeira, o presente trabalho empregou séries históricas disponíveis de precipitação e vazões do Rio Cachoeira e seus tributários com vistas a estimar a disponibilidade hídrica e o balanço hídrico.

\section{CARACTERIZAÇÃO DA ÁREA DE ESTUDO}

A Bacia Hidrográfica do rio Cachoeira (BHRC) Contas e Almada, a sul pelas bacias dos rios Pardo na região de Itabuna (Figura 1), sul do estado da Bahia, ocupa área de $4382 \mathrm{~km}^{2}$, com $181 \mathrm{~km}$ de extensão do rio principal e desnível de $720 \mathrm{~m}$. A BHRC está limitada a norte pelas bacias dos rios e Uma, a oeste pela bacia do rio Pardo e a leste pelo Oceano Atlântico (CEPLAC, 1976). A BHRC abrange 10 municípios do sul da Bahia, onde vivem cerca de 600.000 habitantes.

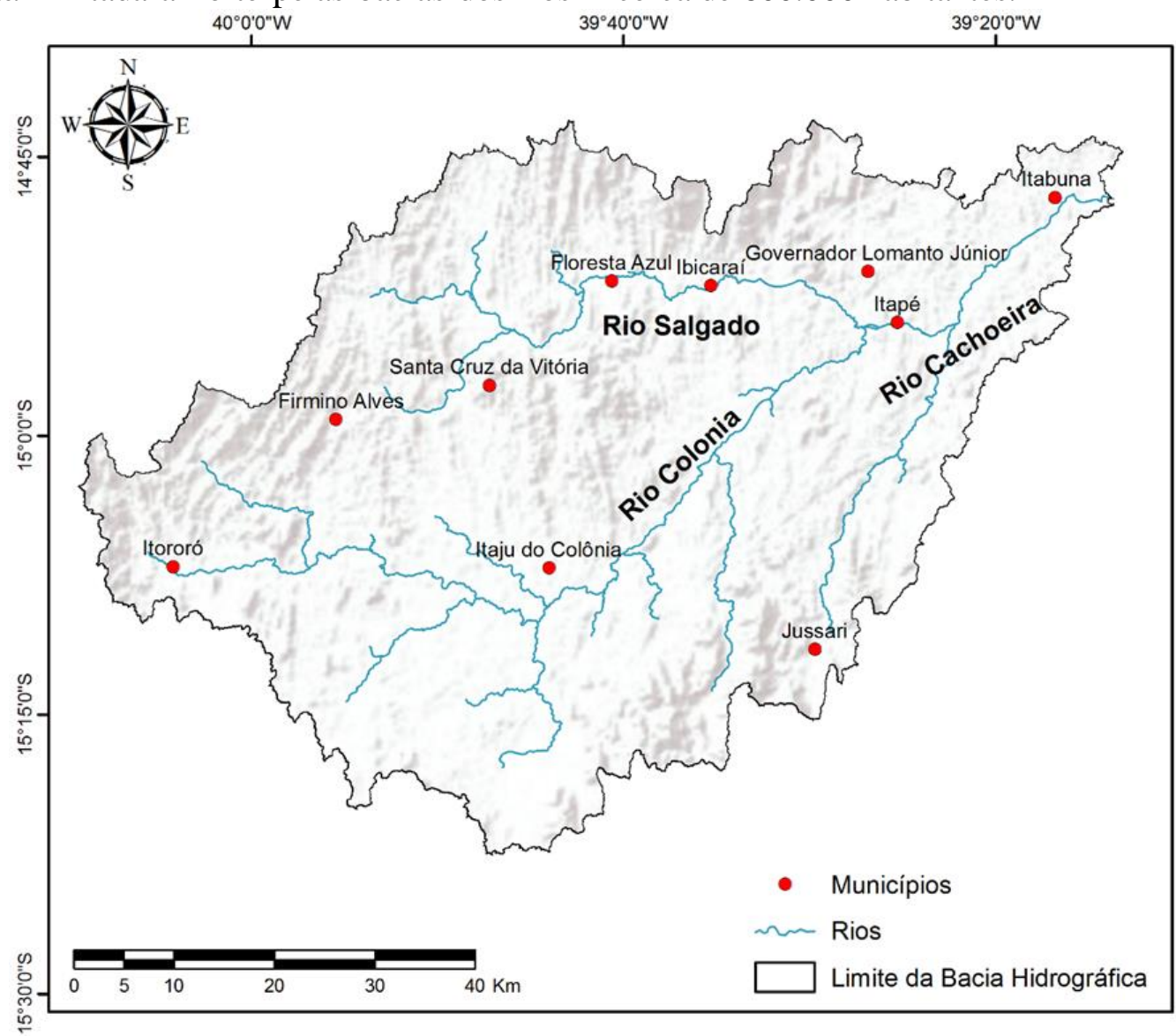

Figura 1 - Bacia hidrográfica do rio Cachoeira. 
Os principais rios da BHRC são: o Rio Salgado, que nasce na Serra do Salgado e no seu curso de 64 km banha os municípios de Firmino Alves, Santa Cruz da Vitória, Floresta Azul, Ibicaraí e Itapé; o Rio Colônia, que nasce na Serra da Ouricana e estende-se por $131 \mathrm{~km}$, banhando os municípios de Itororó, Itaju do Colônia e Itapé; o Rio Piabanha, que atravessa o município de Jussari; e Rio Cachoeira, que nasce da confluência dos rios Colônia e Salgado e, em seu percurso de $50 \mathrm{~km}$, banha os municípios de Itapé, Itabuna e Ilhéus (IBGE, 1999).

Geologicamente, a Bacia do Rio Cachoeira está localizada no domínio Itabuna-Salvador-Curaçá, composto pelo cinturão de Itabuna, ao sul, e Salvador-Curaçá, ao norte (Pinho, 2005) (Figura 2). Estas unidades são formadas por granulitos tonalíticos e trondhjemíticos, subdivididas em séries toleíticas, cálcio-alcalinas de baixo potássio, e shoshoníticas, associadas a bandas metassedimentares e basaltos e gabro-oceânicos e/ou de bacias back-arc (Barbosa \& Sabaté, 2002).

A suíte intrusiva de Itabuna originou-se do magmatismo pós-tectônico, de idade neoproterozoica, cujas rochas de natureza alcalina formam corpos de sienitos, nefelina-sienitos, sodalitasienitos, monzodiorito, leucogabro, diorito e norito (Arcanjo, 1993).

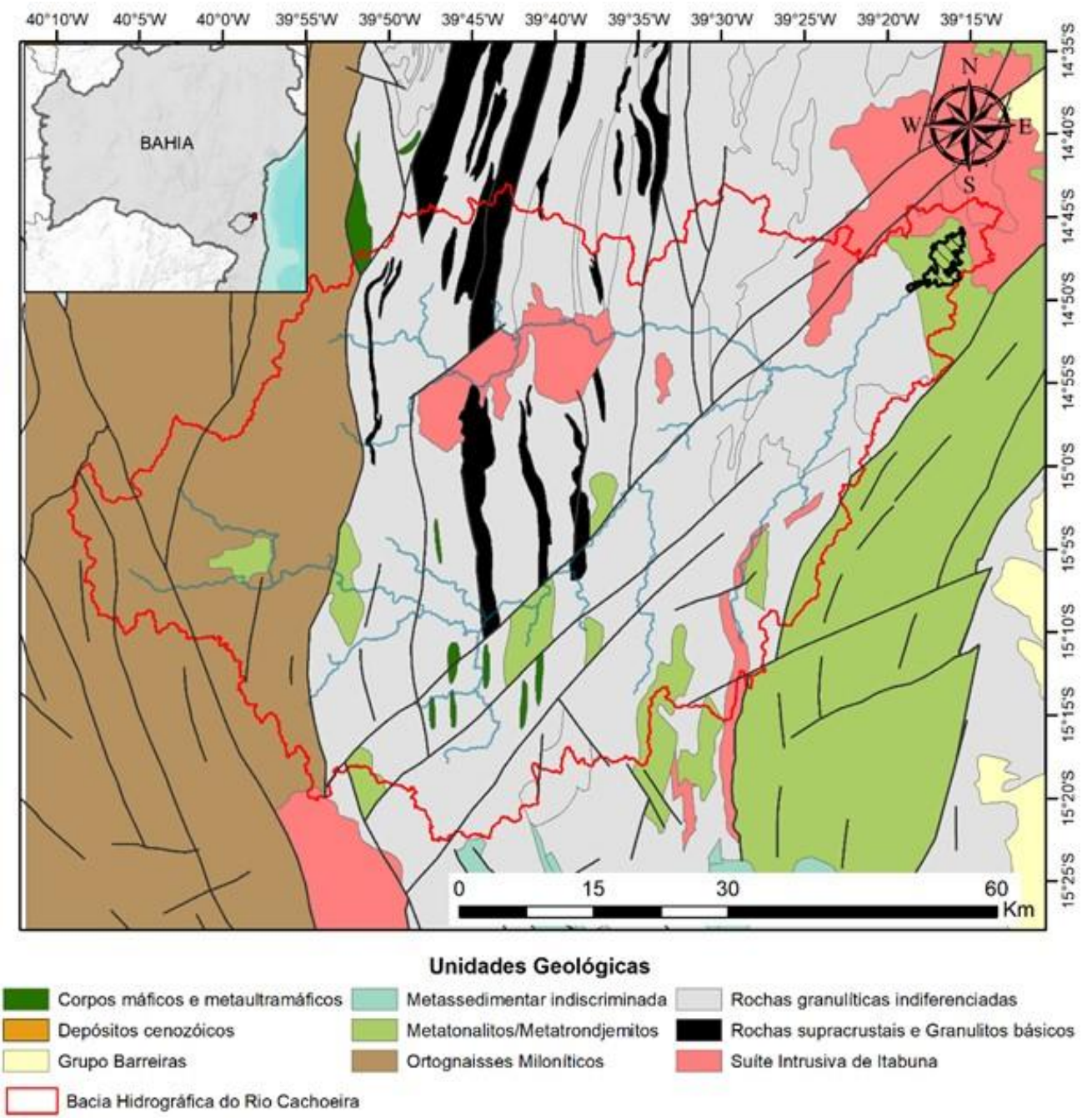

Figura 2 - Mapa geológico do Cinturão Itabuna-Salvador-Curaçá (Pinho, 2005).

O clima na Bacia do Rio Cachoeira, segundo a classificação de Köppen (1936), varia de leste para oeste, passando de clima tropical úmido (Af), a clima de monção (Am) e clima tropical com estação seca de Inverno (Aw).

A pluviometria na BHRC apresenta grande variação espacial, com os menores índices pluviométricos registrados no interior da bacia e aumento gradativo da precipitação em direção ao litoral (Figura 3).

Em Itabuna, Itapé, Ibicaraí e Jussari predomina clima equatorial, com precipitação mensal média superior a $60 \mathrm{~mm}$, cujo período chuvoso ocorre entre os meses de novembro a abril. Na porção centro-oeste da bacia, em Itaju do Colônia, Itororó e Itapetinga, predomina clima tropical semi-úmido com estação seca entre maio e outubro e período chuvoso de novembro a abril. 


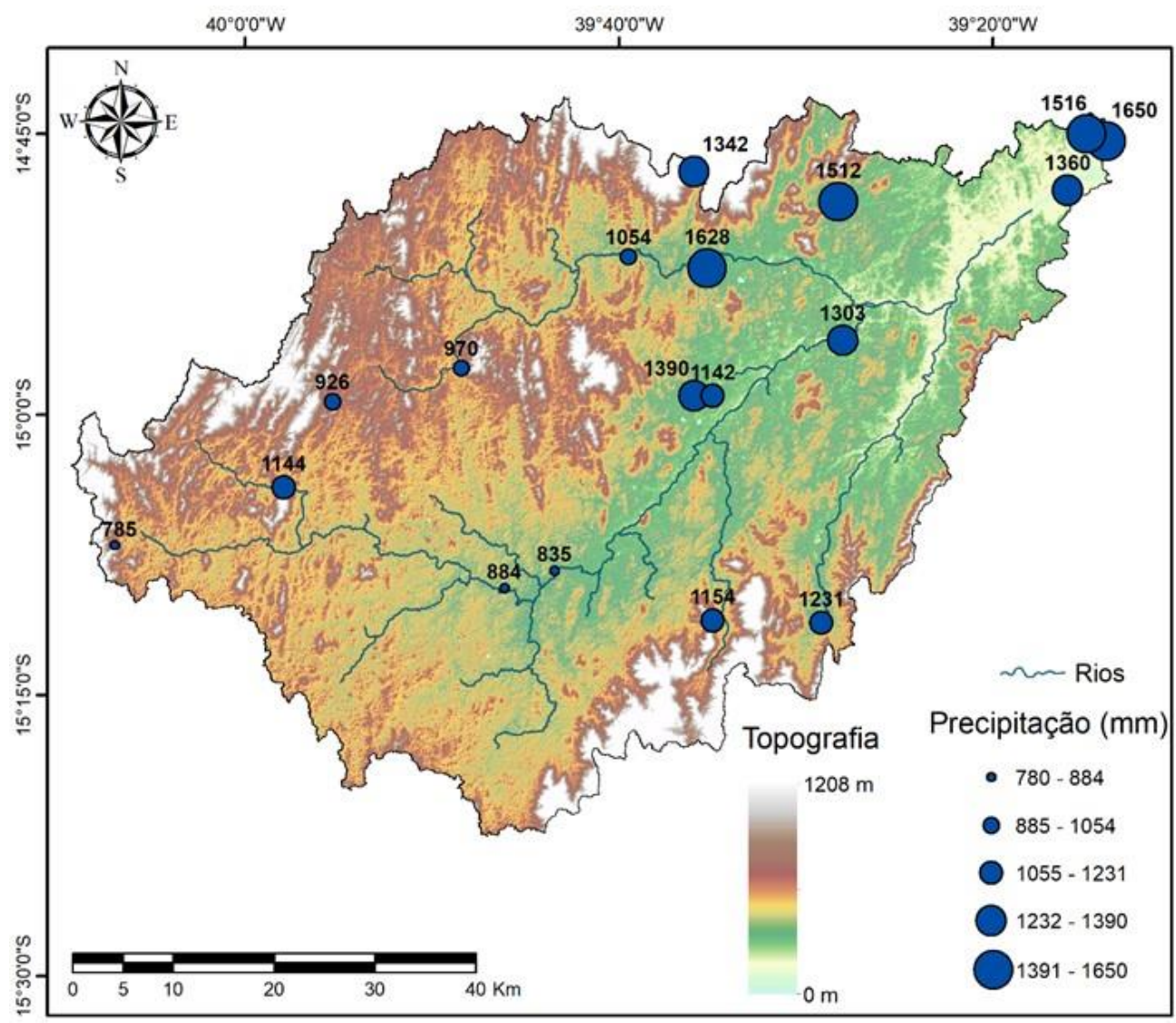

Figura 3 - Distribuição das estações pluviométricas catalogadas pela ANA com os valores de precipitação média anual.

\section{MATERIAIS E MÉTODOS}

\section{Estações pluviométricas e fluviométricas}

Para os cálculos de estimativa da disponibilidade hídrica superficial e do balanço hídrico na bacia hidrográfica do rio Cachoeira foram selecionados um posto fluviométrico e cinco estações pluviométricas (Figura 4). A área de drenagem da estação fluviométrica foi delimitada por meio do software ArcGIS 10.0 $\left(\right.$ ESRI $\left.^{\mathrm{TM}}\right)$, utilizando imagens ASTER-GDEM (Advanced Spaceborne Thermal Emission and Reflection Radiometer - Global Digital Elevation Model) com resolução espacial de 30 metros.

A série histórica dos dados foi obtida no aplicativo Hidroweb, mantido pela Agência Nacional de Águas (ANA). O tratamento das séries históricas e o cálculo das variáveis hidrológicas foram efetuados pelo aplicativo Hidro 1.3, desenvolvido pela ANA. A análise dos dados restringiu-se ao período de 1973 a 2005, período em que a estação fluviométrica avaliada apresenta dados consistentes, com poucos intervalos de falhas.

\section{Disponibilidade hídrica}

A análise regional da disponibilidade hídrica na bacia do rio Cachoeira foi pautada em parâmetros inertes aos efeitos sazonais e de curto-período, permitindo reconhecer padrões e tendências regionais de longa duração. As variáveis hidrológicas empregadas para avaliação da disponibilidade hídrica superficial correspondem aos valores da vazão mínima de referência $\left(\mathrm{Q}_{7,10}\right)$ e à curva de permanência de vazão do rio.

A vazão mínima de referência $\left(\mathrm{Q}_{7,10}\right)$ define a menor vazão anual de sete dias consecutivos, com recorrência de 10 anos.

$\mathrm{O} \mathrm{Q}_{7,10}$ é um importante parâmetro hidrológico que fornece a estimativa estatística da disponibilidade hídrica de cursos d'água e corresponde a um valor que, em média, a cada 10 anos, será igualado ou inferiorizado pelo escoamento médio de estiagem do rio em sete dias consecutivos. $\mathrm{O}$ valor de $\mathrm{Q}_{7,10}$ foi estimado através do método de distribuição estatística de Weibull, método descrito detalhadamente em Tucci (2004).

A curva de permanência relaciona a vazão com a porcentagem do tempo em que esta é superada ou igualada durante o período avaliado. Usualmente, a disponibilidade hídrica da bacia está associada a vazões com permanência em 90\% (Q90) e 95\% (Q95) da série histórica analisada (ANA, 2005).

Para o cálculo da disponibilidade hídrica superficial para abastecimento público do 
município de Itabuna foram considerados os dados da estação 5318000, exutório da bacia hidrográfica, a taxa de captação $150 \mathrm{~L} / \mathrm{s}$ utilizada no abastecimento público (Itabuna, 2014), e as vazões de referência correspondentes ao $\mathrm{Q}_{7,10}$ e a curva de permanência.

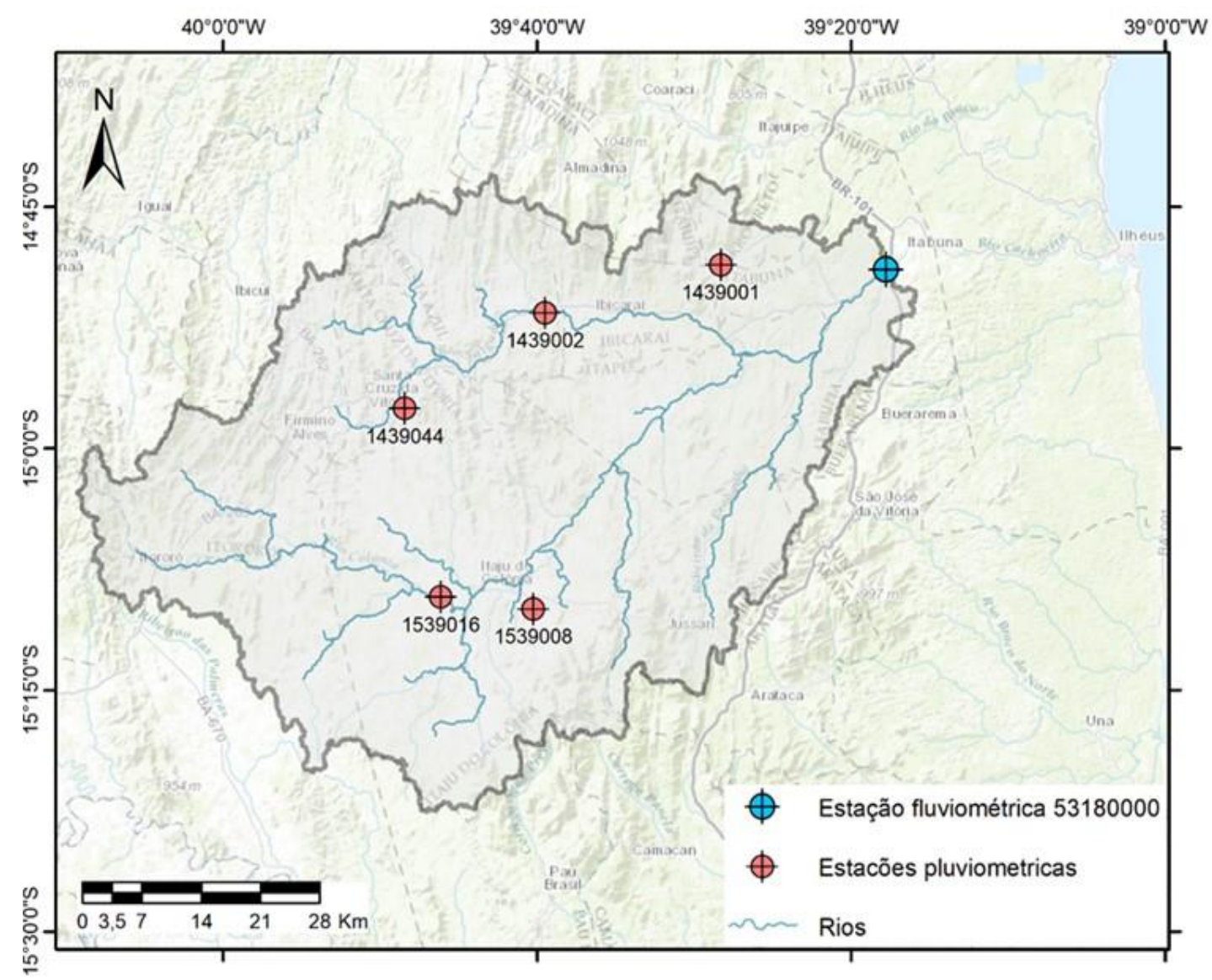

Figura 4 - Bacia Hidrográfica do Rio Cachoeira com a localização das estações pluviométricas e fluviométricas utilizados neste trabalho.

\section{Balanço hídrico}

O balanço hídrico relaciona os componentes do ciclo hidrológico aos princípios da continuidade e conservação de massa, segundo o qual a diferença entre as entradas e saídas corresponde à variação do armazenamento no sistema.

Considerando a bacia hidrográfica um sistema fechado que atua como um reservatório de água, tem-se a transformação da precipitação em escoamento superficial e subterrâneo e a perda de água por meio da evapotranspiração. Quando se analisa um período longo de dados, o armazenamento de água na bacia pode ser desprezado, uma vez que os valores estatísticos médios compensam a variação de valores das séries históricas. Assim, o balanço hídrico de um sistema em equilíbrio pode ser expresso pela Equação 1.

$$
P=E s+E b+E v
$$

Onde $\mathrm{P}$ é a precipitação, Es é o escoamento superficial, Eb é o escoamento de base e Ev é a evapotranspiração.

A precipitação acumulada na bacia hidrográfica foi calculada com base nos dados das estações pluviométricas 1439001, 1439002, 1439044, 1539008 e 1539016. As isoietas médias mensais e anuais foram traçadas a partir da interpolação dos dados dessas estações pelo método do inverso da distância, utilizando-se o software ArcGIS 10. As precipitações mensais e anuais médias da bacia foram obtidas pela ponderação das áreas interceptadas pelas isoietas.

Para o cálculo dos escoamentos de base e superficial foi utilizada a técnica de filtros digitais (Pettyjohn \& Henning, 1979), que permite separar, de maneira automatizada e sistemática, a contribuição dos escoamentos de base e superficial.

Foi empregado o método de mínimos locais (Sloto \& Crouse, 1996), utilizando o aplicativo BFI (Eckhardt, 2005), que produz estimativas diárias dos componentes do fluxo de base e do escoamento superficial. 


\section{RESULTADOS}

\section{Balanço Hídrico}

A aplicação de filtros digitais aos dados de vazão média diária do rio cachoeira e o tratamento e interpolação dos dados pluviométricos permitiram estimar as médias mensais das vazões de base (Eb) e superficial (Es) (Figura 5) e a precipitação (P) (Figura 5) na bacia hidrográfica. Conhecidas essas variáveis, foi possível calcular a evapotranspiração (Ev) da bacia do rio Cachoeira.

Os resultados do balanço hídrico, apresentados na tabela 1 e na figura 6 , mostram a baixa contribuição do aquífero na regularização da vazão do rio Cachoeira, sendo, em média, $15 \%$ da vazão do rio, e a elevada perda de água da bacia hidrográfica por evapotranspiração.

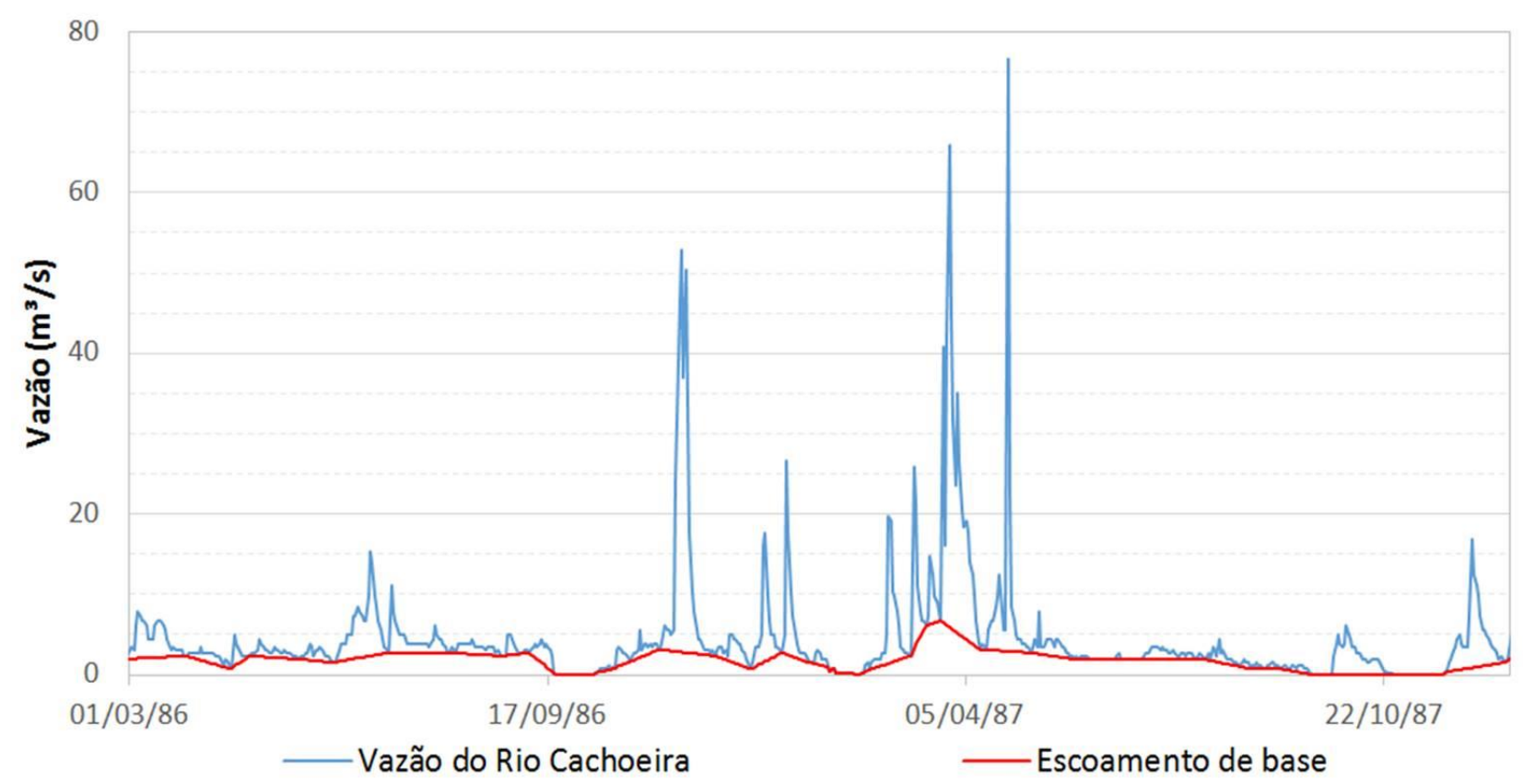

Figura 5 - Hidrograma do Rio Cachoeira mostrando a contribuição do escoamento de base (em vermelho) e do escoamento superficial (área delimitada pelas linhas vermelha e azul).

Tabela 1 - Parâmetros hidrológicos do balanço hídrico mensal da BHRC na estação 5318000.

\begin{tabular}{c|c|c|c|c|c|c|c|c|c|c|c|c|c}
\hline Parâmetro & Jan & Fev & Mar & Abr & Mai & Jun & Jul & Ago & Set & Out & Nov & Dez & $\begin{array}{c}\text { Média } \\
\text { Anual }\end{array}$ \\
\hline P $(\mathbf{m m})$ & 116,13 & 105,64 & 125,75 & 106,51 & 76,93 & 75,39 & 77,59 & 57,24 & 59,23 & 86,31 & 136,64 & 146,95 & $\mathbf{1 1 7 0 , 3 1}$ \\
\hline Et $(\mathbf{m m})$ & 20,89 & 22,60 & 25,40 & 13,57 & 8,03 & 7,26 & 7,75 & 5,50 & 4,61 & 7,24 & 22,61 & 31,31 & $\mathbf{1 7 6 , 7 8}$ \\
\hline Eb $(\mathbf{m m})$ & 2,39 & 2,18 & 2,98 & 2,47 & 2,25 & 2,32 & 2,25 & 2,14 & 1,74 & 1,68 & 2,48 & 2,44 & $\mathbf{2 7 , 3 5}$ \\
\hline Es $(\mathbf{m m})$ & 18,49 & 20,41 & 22,42 & 11,10 & 5,78 & 4,94 & 5,50 & 3,36 & 2,88 & 5,56 & 20,13 & 28,86 & $\mathbf{1 4 9 , 4 3}$ \\
\hline Ev $(\mathbf{m m})$ & 95,24 & 83,04 & 100,35 & 92,94 & 68,90 & 68,12 & 69,83 & 51,74 & 54,62 & 79,07 & 114,03 & 115,64 & $\mathbf{9 9 3 , 5 3}$ \\
\hline
\end{tabular}

Nota: P - precipitação; Et - escoamento total (Eb+Es); Es - escoamento superficial; Eb - escoamento de base; Ev evapotranspiração.

Definidos os parâmetros do balanço hídrico, foram calculadas suas relações hidrológicas mensais (Tabela 2). Embora o índice pluviométrico anual da bacia hidrográfica do rio Cachoeira seja elevado, com média de 1170 $\mathrm{mm} / \mathrm{a}$, a evapotranspiração anual média da bacia hidrográfica perfaz cerca de $85 \%$ da precipitação $(\mathrm{Ev} / \mathrm{P})$, restando apenas $15 \%$ do volume de água precipitado para ser escoado pelos rios e infiltrado no aquífero (Et/P).

$\mathrm{O}$ escoamento superficial representa a maior parcela da água do escoamento total, com média anual de $84,5 \%$ e máximo de $92,2 \%$ no período chuvoso.

Admitindo-se a hipótese de que o fluxo natural de entrada e saída do aquífero são iguais, pode-se considerar a recarga do aquífero igual ao escoamento de base (Eb). Assim, a recarga média anual estimada para o aquífero $(27,35 \mathrm{~mm} / \mathrm{a})$ corresponde a $15 \%$ da vazão média do rio Cachoeira e a $2,3 \%$ da precipitação média anual $(\mathrm{Eb} / \mathrm{P})$. 


\section{Disponibilidade hídrica superficial}

A BHRC apresenta variações sazonais de escoamento dos rios provocadas pelo regime de chuvas diferenciado na região, com estiagem entre os meses de maio e outubro e o período chuvoso entre novembro e abril. Durante a estiagem, a vazão média mensal no rio Cachoeira permanece abaixo de $1,1 \mathrm{~m}^{3} / \mathrm{s}$, enquanto no período chuvoso as vazões médias são superiores a $2,5 \mathrm{~m}^{3} / \mathrm{s}$ (Figura 7 ).

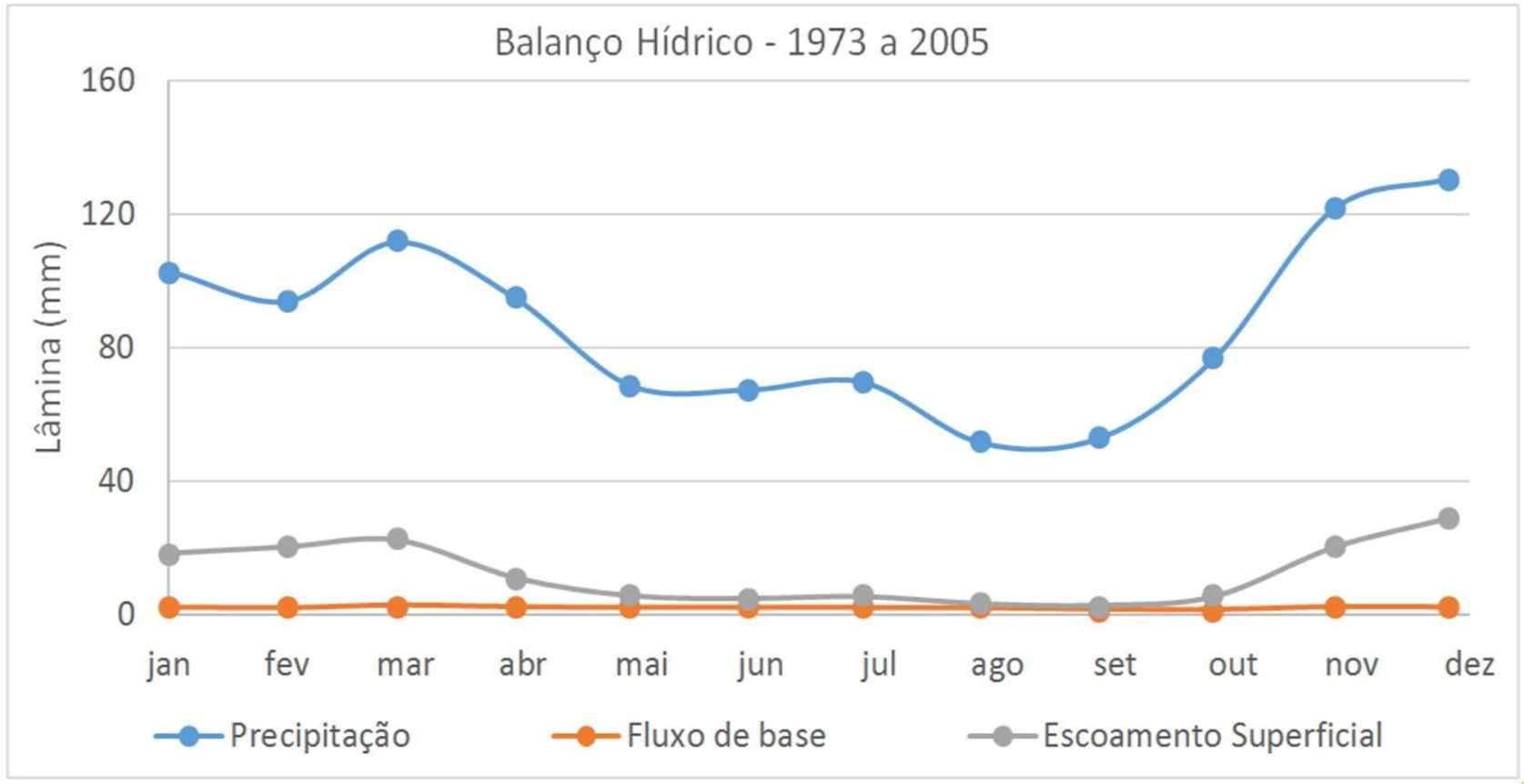

Figura 6 - Gráfico das componentes mensais do balanço hídrico.

Tabela 2 - Relações dos parâmetros hidrológicos do balanço hídrico.

\begin{tabular}{c|c|c|c|c|c|c|c|c|c|c|c|c|c}
\hline Índice & Jan & Fev & Mar & Abr & Mai & Jun & Jul & Ago & Set & Out & Nov & Dez & $\begin{array}{c}\text { Média } \\
\text { Anual }\end{array}$ \\
\hline Et/P & $18,0 \%$ & $21,4 \%$ & $20,2 \%$ & $12,7 \%$ & $10,4 \%$ & $9,6 \%$ & $10,0 \%$ & $9,6 \%$ & $7,8 \%$ & $8,4 \%$ & $16,5 \%$ & $21,3 \%$ & $\mathbf{1 5 , 1 1 \%}$ \\
\hline Ev/P & $82,0 \%$ & $78,6 \%$ & $79,8 \%$ & $87,3 \%$ & $89,6 \%$ & $90,4 \%$ & $90,0 \%$ & $90,4 \%$ & $92,2 \%$ & $91,6 \%$ & $83,5 \%$ & $78,7 \%$ & $\mathbf{8 4 , 8 9 \%}$ \\
\hline Eb/Et & $11,5 \%$ & $9,7 \%$ & $11,7 \%$ & $18,2 \%$ & $28,1 \%$ & $32,0 \%$ & $29,0 \%$ & $39,0 \%$ & $37,6 \%$ & $23,2 \%$ & $11,0 \%$ & $7,8 \%$ & $\mathbf{1 5 , 4 7 \%}$ \\
\hline Eb/P & $2,1 \%$ & $2,1 \%$ & $2,4 \%$ & $2,3 \%$ & $2,9 \%$ & $3,1 \%$ & $2,9 \%$ & $3,7 \%$ & $2,9 \%$ & $1,9 \%$ & $1,8 \%$ & $1,7 \%$ & $\mathbf{2 , 3 4 \%}$ \\
\hline Es/P & $15,9 \%$ & $19,3 \%$ & $17,8 \%$ & $10,4 \%$ & $7,5 \%$ & $6,6 \%$ & $7,1 \%$ & $5,9 \%$ & $4,9 \%$ & $6,4 \%$ & $14,7 \%$ & $19,6 \%$ & $\mathbf{1 2 , 7 7 \%}$ \\
\hline Es/Et & $88,5 \%$ & $90,3 \%$ & $88,3 \%$ & $81,8 \%$ & $71,9 \%$ & $68,0 \%$ & $71,0 \%$ & $61,0 \%$ & $62,4 \%$ & $76,8 \%$ & $89,0 \%$ & $92,2 \%$ & $\mathbf{8 4 , 5 3 \%}$ \\
\hline
\end{tabular}

Nota: Et - escoamento total; Ev - evapotranspiração; Eb - escoamento de base; Es - escoamento superficial, P precipitação

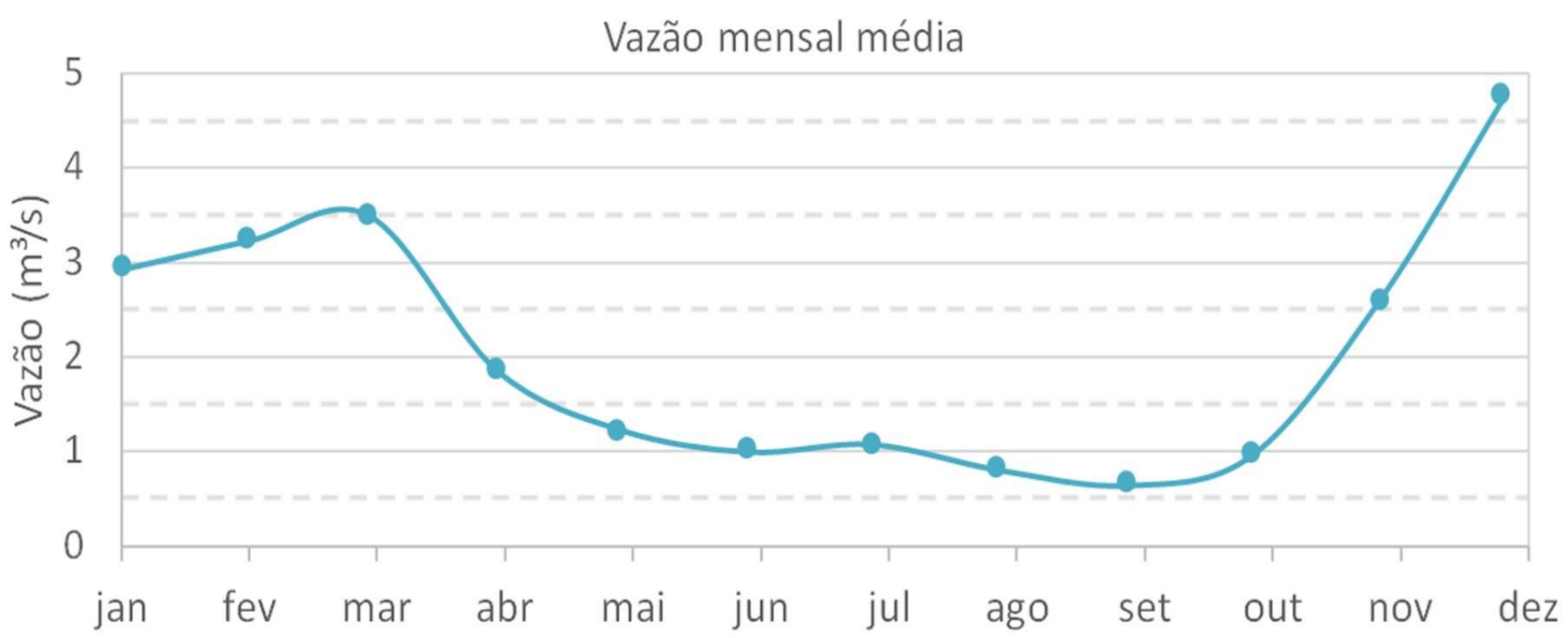

Figura 7 - Vazões médias mensais na estação 53180000. 
A Figura 8 apresenta a curva de permanência calculada para a estação fluviométrica 53180000; a tabela 3 apresenta os valores de referência da vazão de permanência em 95\% (Q95), 90\% (Q90), 85\% (Q85), 80\% (Q80) e 50\% (Q50) do tempo analisado, a vazão mínima de referência $(Q 7,10)$ e a média de vazão da série histórica da estação fluviométricas analisadas.

A curva de permanência indica que em $50 \%$ do período analisado as vazões correspondem a menos de $30 \%$ da vazão média dos rios.

Vazões menores que $0,5 \mathrm{~m}^{3} / \mathrm{s}$ são características de Q95, Q90, Q85 e Q7,10 e indicam pouca contribuição do aquífero na regularização da vazão natural da bacia hidrográfica, cujos picos de cheias representam grande parte do volume de água escoado na bacia.

A análise da curva de permanência do rio revela que vazões inferiores a $150 \mathrm{~L} / \mathrm{s}$, taxa de captação necessária ao abastecimento público, foram recorrentes em $13 \%$ (Q87) da série histórica analisada, indicando insuficiência hídrica para captação de $150 \mathrm{~L} / \mathrm{s}$ em 48 dias, em média, ao longo de um ano. Segundo os índices calculados de vazão mínima de referência do rio, $\mathrm{Q}_{7,10}$, e das vazões de permanência Q95 e Q90, a vazão do rio é insuficiente para atender à demanda hídrica de captação do município de Itabuna.

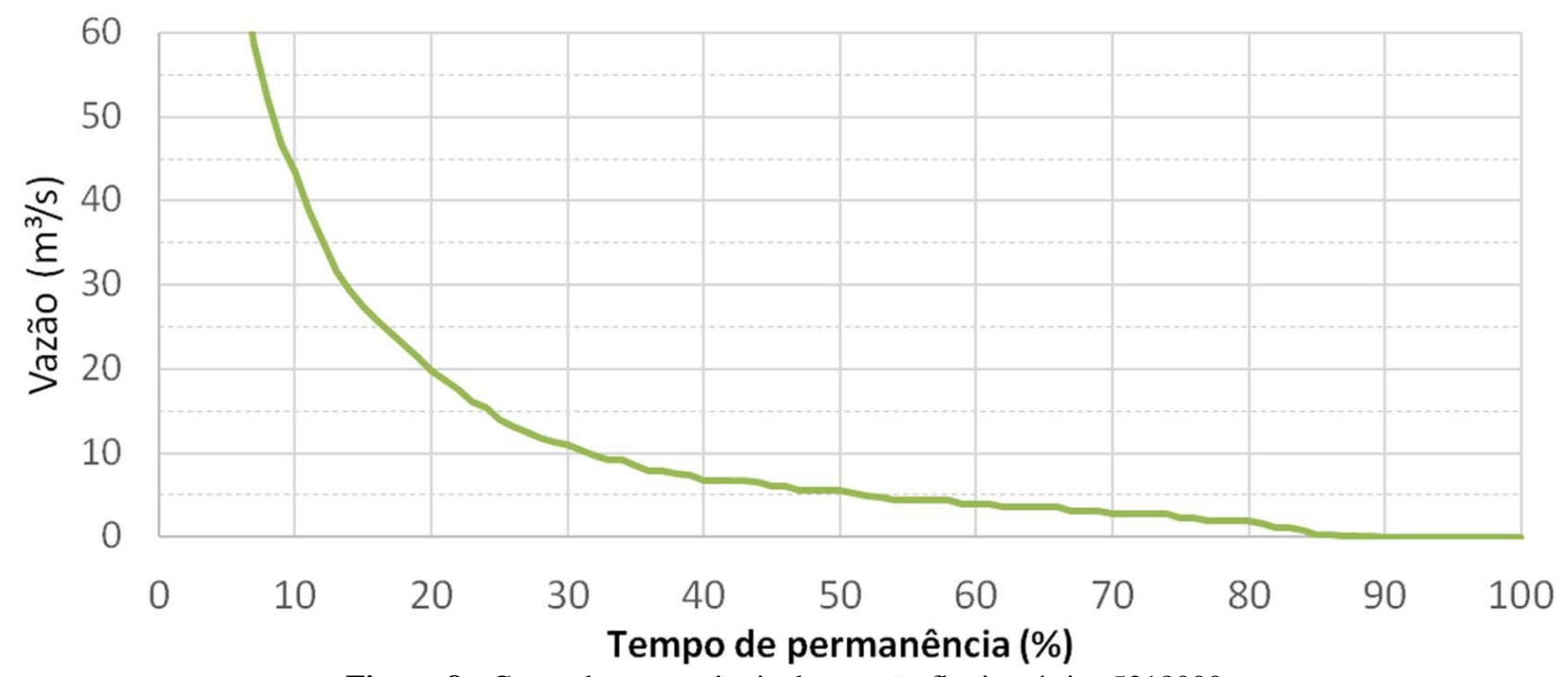

Figura 8 - Curva de permanência da estação fluviométrica 5318000.

Tabela 3 - Vazão média da série histórica, vazões de permanência e vazões mínimas de referência da estação fluviométrica 53180000, no período de 01/01/1973 a 31/12/2005.

\begin{tabular}{|c|c|c|c|c|c|c|c|c|c|}
\hline \multirow{2}{*}{$\begin{array}{c}\text { Estação } \\
\text { fluviométrica }\end{array}$} & \multirow{2}{*}{$\begin{array}{c}\text { Área } \\
\left(\mathbf{K m}^{2}\right)\end{array}$} & \multirow{2}{*}{$\begin{array}{c}\text { Dados } \\
\text { disponíveis no } \\
\text { período }\end{array}$} & \multicolumn{5}{|c|}{ Vazão de permanência (m³/s) } & \multirow{2}{*}{$\begin{array}{c}\mathbf{Q}_{7,10} \\
\left(\mathbf{m}^{3} / \mathbf{s}\right)\end{array}$} & \multirow{2}{*}{$\begin{array}{c}\text { Vazão } \\
\text { média } \\
\left(\mathrm{m}^{3} / \mathrm{s}\right.\end{array}$} \\
\hline & & & Q95 & Q90 & Q85 & Q80 & Q50 & & \\
\hline 5318000 & 4382 & $98.5 \%$ & 0 & 0.005 & 0.352 & 1.94 & 5.53 & 0.021 & 24.5 \\
\hline
\end{tabular}

\section{DISCUSSÃO}

A distribuição de pluviometria dentro da bacia apresenta claro gradiente leste-oeste (Figura 3). Os maiores valores de precipitações acumuladas anuais acima de $1400 \mathrm{~mm} /$ ano na porção leste da bacia, junto à região costeira, declinando progressivamente no interior da bacia até alcançar valores inferiores a $800 \mathrm{~mm} / \mathrm{ano}$ no limite oeste da bacia. Os índices pluviométricos refletem a variação climática dentro da bacia, que passa de um clima semi-úmido, no interior, a um clima tropical, próximo da costa; estão, ainda, relacionados a variações na topografia. As vazões dos rios da bacia refletem as variações nos índices pluviométricos, verificando-se que os rios Salgado e Colônia, formadores do rio Cachoeira, são intermitentes e podem secar por até oito meses durante o ano (CEPLAC, 1976). O escoamento torrencial é característica significativa da BHRC, cujos leitos dos rios são muito amplos, o que provoca intensas e frequentes cheias ao longo do rio Cachoeira (IBGE, 1999).

A curva de permanência (Figura 8) revela pouca contribuição do aquífero na regularização da vazão natural da bacia hidrográfica. Este fato pode estar associado à ausência de um manto de 
intemperismo espesso, que limita o armazenamento de água em subsuperfície e implica em fluxo de base reduzido.

$\mathrm{O}$ balanço hídrico indica que o escoamento total, o escoamento superficial e o fluxo de base representam apenas $15 \%$ do volume de água precipitada, sendo o restante evapotranspirado (Tabela 2). As baixas proporções do fluxo de base e escoamento superficial indicam que a água precipitada não chega às drenagens, mas fica armazenada em depressões do terreno, formando os inúmeros corpos d'água superficiais, dominantes na fisiografia local, que proporcionam ampla evapotranspiração da água. A taxa de recarga estimada pelo balanço hídrico, de 27,35 mm/ano, representa $2,34 \%$ do volume precipitado e é compatível com as baixas taxas de recarga determinadas em bacias hidrológicas situadas em terrenos cristalinos, como descrito por Glesson et al. (2009) e Chesnaux (2013).

A análise do balanço hídrico, aliada à caracterização hidroquímica das águas superficiais e subterrâneas, realizada por Teramoto et al. (2018) na área de estudo, permitem um diagnóstico preciso da circulação de água na BHRC. Na intepretação desses autores, as elevadas concentrações dos íons $\mathrm{Na}^{+}$, $\mathrm{SO}_{4}{ }^{2-}, \mathrm{Cl}^{-}$são provenientes da intensa evapotranspiração, que promove o incremento das concentrações destas espécies químicas na água. As taxas de $85 \%$ de evapotranspiração, aqui estimadas, reforçam tal interpretação. É possível notar que as amostras de água superficial apresentadas por Teramoto et al. (2019) possuem baixa salinidade e se assemelham às amostras coletadas em porções mais rasas do aquífero, indicando que a quase totalidade do fluxo de base do Rio Cachoeira provém da porção superficial do aquífero. Deste modo, as águas armazenadas em porções mais profundas, com concentrações elevadas de $\mathrm{Ca}^{2+}$, $\mathrm{Mg}^{2+}, \mathrm{Na}^{+}, \mathrm{HCO}_{3}^{-}$e $\mathrm{SiO}_{2}$, provavelmente resultantes da intensa interação com os minerais que compõem o arcabouço do aquífero, não contribuem significativamente com o fluxo de base do Rio Cachoeira.

É necessário destacar que o munícipio de Itabuna representa o principal munícipio dentro da Bacia do Rio Cachoeira e passou por secas prolongadas nos últimos três anos, o que torna a discussão sobre os limites da utilização dos recursos hídricos um tema socialmente sensível. Em decorrência da escassez de água superficial e problemas no abastecimento de água foi registrada forte proliferação de poços no munícipio de Itabuna. Contudo, como aqui demonstrado, a captação de água subterrânea representa uma solução paliativa e insustentável a longo prazo, uma vez que as fraturas, embora transmitam água com eficiência, não constituem bons reservatórios e têm reposição deficitária na bacia.

\section{CONCLUSÕES}

Para investigar a disponibilidade hídrica na Bacia do Rio Cachoeira, situada na porção sul do estado da Bahia, foi estimado seu balanço hídrico para o período de 1973 a 2005. Os resultados revelam que a evapotranspiração anual média da bacia hidrográfica corresponde a cerca de $85 \%$ da precipitação, enquanto $15 \%$ desta é escoada pelos rios ou infiltrada em subsuperfície. $\mathrm{O}$ escoamento superficial representa a maior parcela da água do escoamento total, com média anual de $84,53 \%$, e tem baixa capacidade de infiltração no subsolo. A recarga média anual estimada para o aquífero $(27,35 \mathrm{~mm} / \mathrm{a})$ corresponde a $15 \%$ da vazão média do rio Cachoeira e a $2,34 \%$ da precipitação média anual.

Verifica-se que a disponibilidade hídrica e a taxa de reposição por recarga são reduzidas, indicando que o volume de água disponível para captação sustentável, superficial e subterrânea, é bastante restrita. Tal cenário impõe a necessidade de um programa de gestão que contemple estratégias adequadas para o manejo de recursos hídricos superficiais e subsuperficiais.

\section{REFERÊNCIAS}

ANA, 2005. Disponibilidade e demandas de recursos hídricos no Brasil. Relatório técnico, 134 p.

ARCANJO, J.B.A. Programa de Levantamentos Geológicos

Básicos do Brasil. Folha Itabuna SD-24-Y-B-VI. Estado da Bahia. Escala 1:100.000. Brasília. DNPM/ARCANJO, 1993.

BARBOSA, J.S.F \& SABATÉ, P. Geological features and the Paleoproterozoic collision of four Archean crustal segments of the São Francisco Craton, Bahia, Brazil: a synthesis.
Anais da Academia Brasileira de Ciências, v. 74, n. 2, p. 343-359, 2002.

BERKOWITZ, B. Characterizing flow and transport in fractured geological media: A review. Advances in water resources, $v$. 25, n. 8-12, p. 861-884, 2002.

CEPLAC. Diagnóstico socioeconômico da região cacaueira, 5: Recursos hídricos. Rio de Janeiro, Convênio IICA/CEPLAC, 1976, 133p. 
CHESNAUX, R. Regional recharge assessment in the crystalline bedrock aquifer of the Kenogami Uplands, Canada. Hydrological Sciences Journal, v. 58, n. 2, p. 421-436, 2013. DEWANDEL, B.; LACHASSAGNE, P.; WYNS, R.; MARÉCHAL, J.C.; KRISHNAMURTHY, N.S. A generalized 3-D geological and hydrogeological conceptual model of granite aquifers controlled by single or multiphase weathering. Journal of Hydrology, v. 330, n. 1-2, p. 260-284, 2006.

ECKHARDT, K. How to construct recursive digital filters for baseflow separation. Hydrological Processes: An International Journal, v. 19, n. 2, p. 507-515, 2005.

ENGELBRECHT, B.Z. Modelo conceitual de circulação de água subterrânea em aquífero cristalino no município de Itu/SP. Rio Claro, 91 p., 2017. Dissertação (Mestrado) Instituto de Geociências e Ciências Exatas.

GLEESON, T.; NOVAKOWSKI, K.; COOK, P.G.; KYSER, T. $\mathrm{K}$. Constraining groundwater discharge in a large watershed: Integrated isotopic, hydraulic, and thermal data from the Canadian shield. Water resources research, v. 45, n. 8, 2009.

GUIHÉNEUF, N.; BOISSON, A.; BOUR, O.; DEWANDEL, B.; PERRIN, J.; DAUSSEA, A.; VIOSSANGESAS, M.; CHANDRAD, S.; AHMEDD, S.; MARÉCHALC, J.C. Groundwater flows in weathered crystalline rocks: Impact of piezometric variations and depth-dependent fracture connectivity. Journal of Hydrology, v. 511, p. 320-334, 2014

GUSTAFSON, G. \& KRÁSNÝ, J. Crystalline rock aquifers: their occurrence, use and importance. Applied Hydrogeology, v. 2, n. 2, p. 64-75, 1994.

IBGE, 1999. Folha SD.24 Salvador: potencial dos recursos hídricos. Departamento de Recursos Naturais e Estudos Ambientais. Rio de Janeiro. 236 p. - Levantamento de recursos naturais; v. 24.

ITABUNA (BA). Prefeitura, Anuário Estatístico de Itabuna: ano base de 2012. Prefeitura municipal de Itabuna. Secretaria de Planejamento e tecnologia. Itabuna, BA: PMI/UESC, 2014. 265p.
PETTYJOHN, W.A. \& HENNING, R. Preliminary estimate of groundwater recharge rates, related streamflow and water quality in Ohio. Ohio State University. Water Resources Center Project Completion. Report $\mathbf{n}^{\circ}$ 552. Ohio, 323 p., 1979

PINHO, I.C.A. Geologia dos Metatonalitos / Metatrondhjemitos e Granulitos básicos associados das regiões de Camamu-Ubaitaba-Itabuna. Salvador, 2005, 164 p. Tese (Doutorado em Geologia) - Instituto de Geociências, Universidade Federal da Bahia.

RIJSBERMAN, F.R. Water scarcity: fact or fiction ?. Agricultural water management, v. 80, n. 1-3, p. 5-22, 2006 SLOTO, R.A. \& CROUSE, M.Y. HYSEP: A computer program for streamflow hydrograph separation and analysis. U.S. Geological Survey. Water-Resources Investigations Report, 96-4040, Lemoyne, Pennsylvania, 46 p., 1996.

TERAMOTO, E.H.; GONÇALVES, R.D.; STRADIOTO, M.R.; ENGELBRECHT, B.Z.; CHANG, H.K. Modeling Rock-Water Interaction of Fractured Aquifer in Itabuna/BA Region. Anuário do Inst. Geociências - UFRJ, v. 42, p. 735-741, 2019. doi:10.11137/2019_1_735_741

TUCCI, C.E.M. Hidrologia: ciência e aplicação. 3.ed. Porto Alegre: ABRH, 2004, 943 p. 